\title{
Klangfarbenmelodie: Learner Identity and the Creative Arts
}

\author{
Sophia Xiang
}

\begin{abstract}
Written from the perspective of a Grade 5/6 French Immersion teacher, this paper examines the role of music, poetry, and the visual arts in enhancing learner identity, in the context of the elementary school classroom. It begins with a focus on artistic metaphors that represent cultural and linguistic hyphenation. It then addresses practical applications of these metaphors into classroom activities, projects, and lessons, enhancing community, academic curricular goals, and student self-awareness.
\end{abstract}

\section{Background}

Two of the most inspirational people in my life were school teachers. Through their teachings, community-building, their pushing me beyond my academic and artistic comfort zones, and their modeling of hard work and passion, I was inspired to pursue the creative arts and education. I am currently a French Immersion teacher in a Grade 5/6 classroom and a choir director, and owe much of my teaching style to their inspirational ways.

Mr. J's teaching style was unconventional, hands-on, and challenging. He taught English literature and creative writing, and all of my best memories of him extend beyond the classroom. Every month, he took us to the productions of UBC Theatre at the Frederic Wood Theatre (affectionately nicknamed "Freddy Wood" by Mr. J). The next morning, he taught us how to dissect and deconstruct meaning as we would analyze quotes, set design, plot, and character development. Mr. J took us to Gambier Island and to Ucluelet for overnight trips and writing workshops, where he invited us to walk off for a few hours into the wild and write and create. When we came back together, he would light a fire and encourage us to read our works to each other. Some students took out their guitars and sang their works out to the group, performing them timidly but passionately.

After lights-out on Gambier Island, I sat down at an old, charmingly out-of-tune piano and played songs by The Beatles, Elliott Smith, and Joni Mitchell with a new group of friends that played guitar, ukulele, and that harmonized beautifully. Instead of telling us to hush up because it was already 2 a.m., Mr. J pulled out his banjo and joined us. This authentic, artistic, safe sense of community felt magical. I was in awe. I will be discussing this identity-affirming creation of space, with references to Bhabha (1994), later in this paper.

At the end of my undergraduate studies, I lived and studied in Paris. Life felt like a dream when in the mornings, I would study the writings of Baudelaire and Apollinaire in the lecture hall, and in the afternoons, I would walk through the cemeteries, kept like beautiful gardens, stopping by their graves. 
I became a French Immersion teacher soon after this. Mr. J is now retired and spends his days writing books and traveling. We have regular talks and laughs over coffee and tea, and he is a special guest lecturer in my classroom. My students adore him, and always eagerly await his next visit.

I was put into Mr. B's choir class because of initial bad luck - the spots in a drama class that I was hoping to take were full. Overhearing me tinkering around on the piano one day before class began, he appointed me as his accompanist for choir, and he wanted to recruit me for his jazz orchestra, because he said that I had an ear for improvisation. It was thanks to Mr. B's hard work and encouragement that I broke out of my traditionally classical roots and began exploring jazz and rock music. Having grown up learning piano from a rigid, traditional, and classical teacher, and scared to commit myself to more musical intensity, I declined his invitation. However, over several conversations, he pushed me to give it a try, and I finally did. It was one of the best decisions I could have made as a young teenager, since through his music program I met some of my best friends, felt enveloped in a sense of community and belonging, and gained the confidence that I needed to pursue music and performance at a professional level. I will address and explore my definition of this identity-affirming community, safe space, thirdspace (Bhabha, 1994) later in my paper.

At the time, I didn't know it yet, but Mr. J and Mr. B's teachings were helping shape the basis of my identity and teacher identity. I am the teacher that I am today because of many things, but if it hadn't been for Mr. B's enthusiasm for exposing me to the richness of genres beyond classical music, musical collaboration, and for Mr. J's quest to ignite joy and friendship through reading and writing, then I am certain that I would be a different educator.

\section{Locating the Questions}

Through my inspiring, critical experiences as a learner and a teacher, my two central questions were formed. First, how can the creative arts reflect, complement, and enhance learner identity? Second, through the creative arts, how can teachers create a safe space for students to explore cultural and linguistic hyphenation?

Although some educators may view the creative arts as a door that should be opened only periodically, I strongly believe that integrating the arts across the curriculum allows for stronger academic engagement, as well as an enhanced understanding of learner self-identity. In this paper, I will be focusing on music, poetry, and the visual arts. I will begin by highlighting some artistic metaphors that represent cultural and linguistic hyphenation. I will then address practical applications of these metaphors into classroom activities, projects, and lessons.

\section{Klangfarbenmelodie and Hyphenation}

The musical term klangfarbenmelodie is German for tone-color-melody. It was coined by the Expressionist composer, Schoenberg, in 1911. In musical composition, the term describes the texture and color that is added to a work due to the splitting of a melodic line among several instruments. 
Klangfarbenmelodie challenges traditional rules of musical composition, because a melodic line is traditionally assigned to one instrument, or a group of instruments that are the same.

Kursell (2013) notes that

in the resulting sound, a listener cannot pick out the colors of individual instruments. Instead they are merged into a new, previously unheard color. The harmonic progression is in the service of this sound creation. It does not follow the rules of harmonic progression, but freely adds sound to sound. This happens in a fashion that juxtaposes and overlaps the tones so as to create dissonant and unruly chords that do not immediately evoke the demand of harmonic resolution in expert listeners. The harmonic effect that typically makes chords gravitate toward a continuation is suspended. Rather than traditional harmony, the listener hears a harmonious flow of shimmering sound shades. (p. 210)

On a metaphorical level, this musical term is important to my teaching practice because it represents the cultural and linguistic hyphenation that is present in my students. Not only do I teach in a French Immersion environment, but many of my students, like me, are trilingual and are either immigrants or First-Generation Canadians. Poetically, klangfarbenmelodie reminds us that the beauty of learner identity can exist in areas of dissonance and atonality, but that it is in these areas that creation and artistic development may occur.

On a practical level, the term klangfarbenmelodie is used in this paper to highlight the three main avenues of the creative arts that I will be exploring. Klang (tone) will represent music for obvious reasons, farben (color) will represent the visual arts, as much of the beauty in the visual arts is found in shading, color, and lines, and melodie (melody) will represent poetry. I see the writing of a poetic line much like the composition of a musical line: melody focuses on the sequence and relationship of notes to one another, much like poetry's form relies heavily on style and syntax. Klangfarbenmelodie inspires a synesthetic sense of artistic receptivity; I will note that the categories of music, poetry, and visual arts in this paper will not be static. Often, categories will blend into each other (e.g., I will describe a poem that has roots in visual arts, or I will describe a musical recording that was inspired by text) as artistic expression is often inspired and influenced by an overlapping of the senses.

The concept of cultural and linguistic hyphenation connects with Klangfarbenmelodie, as both concepts honor the in-between space; for Klangfarbenmelodie, the space where the senses intertwine, and for hyphenation, the space where cultural identities and expressions interact. Fred Wah (1992), a Canadian poet who is three-quarters Caucasian and one-quarter Chinese, refers to hyphenation as "the ability to remain within an ambivalence without succumbing to the pull of any single culture (resolution, cadence, closure)" (p. 38) It accesses and honors the in-between space, the hyphen; the space where documentarian Nakagawa (2005) ponders: "In Canada, diversity often means 'one ethnicity + hyphen + Canadian,' but what if you don't fit into an easy category? What if your background is a hybrid of ancestries and you live somewhere between, where cultural identities overlap?" 


\section{Learning and Engaging in Music}

Students in Grade 6 and Grade 7 at my school begin to receive formal, classical musical training through the school band program. For some students that did not receive instruction in an extracurricular home setting, or that don't participate in choir, it is their first exposure to learning to play music. Through instruction by the band teacher, students learn to read classical notation, write simple musical phrases, and perform composed pieces at least twice a year. Some students find immense joy in the band program, excited to go to band class every week, and practicing nightly. Some students, however, claim to be "bad at music" because they have failed a playing test or two, and leave their band instruments at school every night because they don't enjoy playing them.

Because many pedagogical methods of music instruction are very product-based rather than processbased, this fixed mindset that develops is unsurprising. These methods are very effective in encouraging students that are already excelling in music and performance, but can be detrimental to students that struggle with performing under pressure. In my journey as a music student, I learned to improvise long after I learned to perform sonatas, nocturnes, and preludes. Because of Mr. B's passion for jazz music, he introduced me to soloing and improvising within a jazz setting, and ultimately to trust my musical instincts within an unfamiliar context.

Sansom (2001) writes about the use of sand, glue, and burlap in the improvisatory process, saying "...the use of musical instruments in unconventional ways and more unusual sound sources (from children's toys to homemade electronic devices) has become established means of sound-production in freely improvised music" (p. 32) He compares this process to Jackson Pollock's action-painting. Using less traditional instruments would allow students to explore sound and creation in a less intimidating format.

In the same article, Sansom (2001) also states,

The emphasis upon process and material qualities enabled by 'freedom' from the image and more (traditionally) formal concerns is paralleled by 'freedom' from functional harmony and/or traditional modes of compositional construction, resulting in direct engagement with the medium of sound and the process of musical creation. (p. 32)

Although I believe that it is essential to teach improvisation skills and moving freely around a musical structure, I still believe that it is essential to teach traditional musical theory, technique, and practice habits. Breaking out of what students perceive as "right" or "wrong" ways of playing is crucial for the expansion of creative thought, collaboration, and openness to composition.

Skills taught in jazz improvisation can be transferred into musical activities that are accessible by the untrained musician. Listening, repeating, echoing, interpreting, playing a simple variation of rhythms can be practiced in a drum circle (e.g., with djembes, congas, and bongos).

For students with a more complex musical background, jazz improvisation can be taught in choir. Vocal scat patterns can be taught, and students can improvise on a simple I-IV-V-I chord pattern. 
Because the focus of musical improvisation is often process-based rather than product-based, the practical classroom applications here will focus on the skills learned during the production of music.

Shifting between traditional musical pedagogy and more process-based practices would reinforce a growth mindset in students that are limited by stage fright and that are limited by their technical musical

competencies. In this framework, assessing students on their abilities to think on the spot while adhering to some aspects of form (e.g., keeping a steady tempo and staying in the same musical key, while inventing a melody without written notation) can be the focus for some lessons, as opposed to marking them on their abilities in performance (e.g., playing a composition note-for-note in a concert setting). This would help shape a safe space where students can feel receptive to new information and open to taking risks in learning.

\section{Learning and Engaging in Square Word Calligraphy and Calligrammes}

For students that feel as if they are floating in between two or more cultures, for students that feel as if they are living and learning between two languages, and for students that feel like their identities are beautifully chaotic and sometimes confusing, they may find comfort and understanding in the structure of artist Xu Bing's Square Word Calligraphy.

Bing (as cited in Harper, 2003) states:

The absurdity of Square Word Calligraphy is that it takes two different words from two completely unrelated language systems and fuses them together into one entity. If you use existing concepts of Chinese or English to try and read or interpret these characters, you won't succeed. The total disconnection between outer appearance and inner substance places people in a kind of shifting cultural position, an uncertain transitional state. (p. 47)

Xu Bing's work challenges the viewer's conceptions of Western and Eastern writing systems, as at first glance, his characters appear to be Chinese. However, upon further examination, the characters, if read as Chinese, are meaningless. The strokes are misleading because they use the techniques that are applied in traditional Chinese writing.

This system of writing is described by de Mul (2011) as a "fusion of two linguistic horizons," and "a humorous comment or critique on asymmetry that often characterize the fusion of horizons (for example, when the discussion between a Chinese and English speaker takes place in English)" (p. 654).

A space of cultural and linguistic discomfort is created intentionally here. The viewer is engaging in an artistic space that is straddling the barriers between Chinese and English, as well as between picture symbols and letters. This space of hyphenation floats between two languages and traditional systems of writing. Square Word Calligraphy, in its form, celebrates the in-between space, and challenges the viewer with it as well. 
Is it possible to elevate the viewer from discomfort once meaning is understood: although the brush strokes are inspired by traditional Chinese calligraphy, Western words are actually embedded within each invented character.

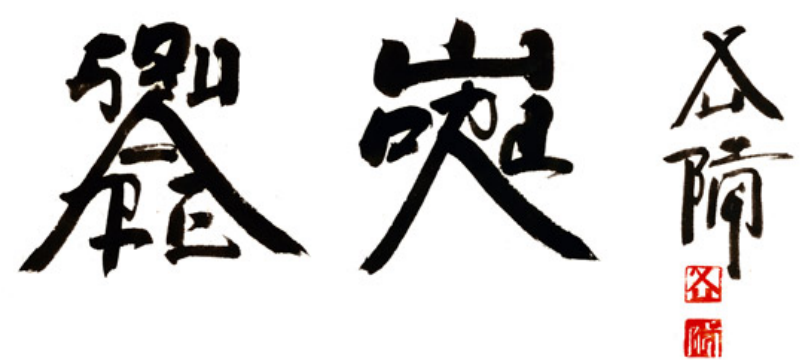

Fig. 1: Xu Bing's Square Word Calligraphy. From Asian Art Archive in America, Square Word Calligraphy, 2011, from http://www.aaaa.org/events/xu-bing-square-word-calligraphy-classroom/

In a classroom setting, simple examples of Xu Bing's work can be displayed either on projector or by passing around books. Without any context or background information, students can be invited to answer questions such as, "What do you see? What do these paintings remind you of? Can you make any connections to what is on the paper?"

Eventually, the hidden English language within the Chinese-inspired strokes will be revealed to the students by the teacher. This can serve as an excellent hook to students' linguistic backgrounds and stories. Guided discussion questions include: "Do you speak any languages other than English and French? Have you ever been in a situation where you didn't understand the languages spoken? How did it make you feel? Do you ever mix up the languages that you can speak? Do you ever feel as though you are floating in between two cultures? Do you feel that different parts of your personality show when you use different languages? When was the last time that you felt uncomfortable due to a language barrier? When was the last time that you felt proud due to crossing a language barrier?"

Much like it is difficult to put Xu Bing's work into a singular box (Is it calligraphy? Is it writing? Is it a painting? Is it truly Chinese? Is it truly English?), it will be difficult to place this lesson into a singular subject area. This fits into the design of BC's New Curriculum extremely well, as the subject areas are becoming more broad and astatic. For example, a unit surrounding Square Word Calligraphy could touch on inventions related to writing and printing (science, engineering), the history of Chinese calligraphy, paper making, brush making (social studies), the history of Western calligraphy (social studies), and painting and art interpretation (visual arts).

Art teacher and researcher, Wexler (2001), in her teaching practice, was inspired by the unfamiliarity of $\mathrm{Xu}$ Bing's symbols and used them as a tool for meaning-making with elementary school students. She invited kindergarten students to tell a story through creating their own symbols based on their knowledge of the alphabet, as well as encouraging them to invent their own picture symbols. She worked with fourth-graders in a similar way and found that students that struggle with spelling were receptive to this form of creating new forms of writing. 
Giving students the opportunity to create their own forms of meaning and narratives allows for new avenues of engagement. A student that may not be as receptive to spelling in English and French may view this form as less intimidating, and therefore a safer space of engagement. Square Word Calligraphy may be a way for students with written output difficulties to connect with writing in an artistic structure that is less stressful and frustrating.

In a French Immersion setting, Square Word Calligraphy can also transfer over to the surrealist poetic form of the calligramme. In a calligramme, text represents meaning on its own, but also as a part of a whole picture. For example, in // Pleut by Guillaume Apollinaire, a chain of metaphors describing rain are arranged descending, vertically. This arrangement highlights the falling nature of precipitation and also brings a visual way of accessing text, much like Xu Bing's Square Word Calligraphy. Students would benefit from exposure to Apollinaire not only because of the poetry and aesthetics, but also because of a historical and cultural context. Exploring poems in the Calligrammes form could serve as an entry into a history and art criticism lesson on surrealism. Apollinaire's connection to Paris in the 1920s links closely to artists and thinkers such as Salvador Dali, Gertrude Stein, Ernest Hemingway, and F. Scott Fitzgerald, all stylistically unique and distinctive.

Writing and arranging calligrammes could function as series of lessons that could cross over into the visual arts. The teacher could provide students with a photograph (e.g., of a landscape, of an animal, of a group of people) as a prompt and students could use it as a starting point. This would also provide students with a shared theme, but their varied writings inspired by the same photograph would demonstrate the beauty in possibilities of divergent thinking.

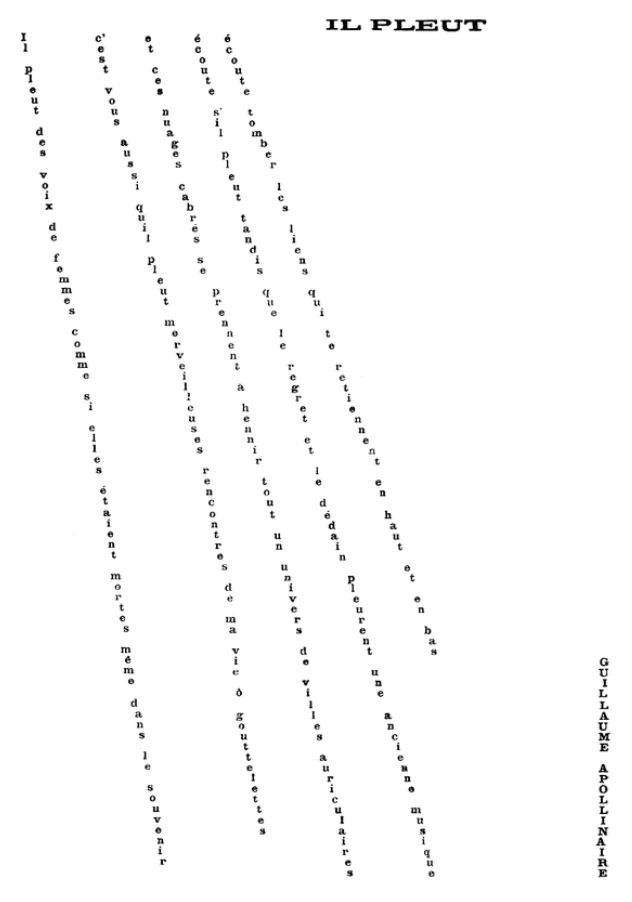

Fig. 2: Il Pleut. From Apollinaire, G., Greet, A. H., \& Lockerbie, S. I. (2004). Calligrammes: Poems of peace and war (1913-1916). Berkeley, CA: University of California Press. 


\section{Learning and Engaging in Poetry}

Through his poetry, Wayde Compton, a local biracial black and white writer, explores ideas of belonging and identity that exist beyond cultural and racial binaries. Compton (2003) is also involved in sound poetry, adding another dimension to his writing through live performances that involve turntablism, manipulating sound with technology. He states:

I enjoy the idea of transforming my voice (myself, that is) into a static disc to be manipulated by the later me, the next me, from above. The remix is a way of-in one moment and one performance-re-enacting the manipulation of history and source culture. In The Reinventing Wheel, this happens in the body of one man made into two voices by the turntables...

The project is a duo of two people and four turntables, The Contact Zone Crew. Compton collaborates and performs with Jason De Couto, a jazz musician and turntablist. Jazz, when looked at structurally, is largely based upon variations and alterations of a musical melody while keeping a very similar harmonic structure, or musical backbone (Compton \& De Couto, 2010). Its unpredictability to the listener is indeed largely based upon creativity and randomness. However, its uniqueness is often limited by some factors, such as the rules of music theory that have roots in some schools of classical music.

Turntablism, the main mode of performance for The Contact Zone Crew, is effective in its variance and distortion of an original melody. Since jazz and turntablism are both genres known for their variations, this remixing of poetry and music is a beautiful way to mimic the cultural, linguistic, and racial remixing that occurs in learner identities.

Upon turning on the radio, sometimes I begin listening to a jazz piece in the middle of it. In many forms of jazz, its main, composed melody is usually played at the beginning and end of a performance. Hearing a complex, improvised musical passage in jazz with limited context, the listener will often ask, "What was the composer's original melody?" It still belongs to the song, although listeners may have a hard time locating it in the composition.

Much like many visual minorities belong to Canada, and are Canadian in culture, their identities as Canadians are still questioned on a day-to-day basis with questions such as, "Where are you really from?" and countless microaggressions dripping with assumptions and prejudices (e.g., "Your English is really good for an Asian person!" "I didn't expect someone from your culture to be the way that you are!")

In Nakagawa's (2005) documentary on Canadian cultural hyphenation, mixed-race poet Fred Wah states,

I'm quite interested in thinking about that notion of the hyphen. That little thing that's in-between. Let's say, "Chinese-Canadian," or "Japanese-Canadian." I like to challenge those two poles, those two hegemonous poles who want to claim a part of me. Because I feel like I've lived in-between and I like the in-between. It's a place that I would like to spruce-up a bit. I like to, you know, put some nice furniture in the in-between place.

It is no surprise that Wah was artistically influenced by jazz music when he was developing his style as a poet. Louis Cabri's description of Wah's work (2009) sounds much like a description of remixing and jazz, "The design [of the poem] itself is part of an ongoing improvisational process that changes the 
design as it goes (but there is always, of course, a design-the improvisational moment does not occur freely, out of nowhere)" (p. 14).

For a Language Arts class, a unit of creative writing can be taught, centering around poetry and creative writing. With a connection to sound poetry, students can be taught about the art of slam poetry. This unit would focus on three aspects: listening, writing, and presenting/oral language.

A strong example of a slam poet is a local writer and performer, Shane Koyczan. I have seen him perform live numerous times, from the main stage of the Vancouver Folk Music Festival to an intimate café on Commercial Drive, Café Deux Soleils. Koyczan's poem, Inconvenient Skin, challenges the celebration of Canada 150 and encourages Canadians to discuss its history of colonialism, injustices, and misuse of power.

The written text alone is powerful (Koyczan, 2017) as it contains lines such as, "150 years/is just us putting birthday candles/on top of smallpox blankets, teen suicides/and missing murdered women," and

we strip, mine, a culture of its identity/allow our leaders to erode each treaty/and stab flags into the land/as if mountains can be owned/as if water is property/where is our dignity/if we cannot hold true to the promises we make?

The recording of Inconvenient Skin adds another layer to the poem, as Koyczan has teamed up with producer Corwin Fox, vocalists Tanya Tagaq (throat singer, of Inuit heritage), and Kym Gouchie (of Lheidli T'enneh heritage). The recording is powerful in its richness, a full sensory experience due to the layering of acapella vocals.

Slam poetry adds another dimension to processing poetry because of the added layer of listening and speaking. Poetry becomes more interactive, as text becomes animated through body language, variations in voice and volume, expression, and pronunciation. This is an effective way for teachers to get in touch with multimodalities. The listening aspect of this activity can be accomplished through cloze (or fill-in-the-blanks) activities, where students are given a copy of the text with blanks where key words should be. Through listening to the recording several times, students are to fill in the words. Once all text is completely written in, the teacher will go over the correct spelling of written words.

This poem is also extremely useful in a social studies context. It links directly to the Grade 5/6 Social Studies curriculum. This poem not only addresses Canadian history, but also poses critical questions. Through the lens of learner identity, it can pose the reader/listener questions of "What does it really mean to be Canadian? Who defines Canada? Who am I as a Canadian? Why are some people labeled more or less 'Canadian' than others?" As many of my students have grandparents, parents, or great-grandparents that are immigrants, this poem could also be an entry point to discussions regarding family history and identity.

There is a vibrant community of slam poets in Vancouver-putting words into action and sound. This could be an engaging way to connect students to the local arts community. WordPlay, run by the Vancouver Poetry House, provides school communities with visits from professional slam poets. 
They have both performances and spoken word workshops, where students are trained to write and perform their own pieces. Field trip ideas can include a visit to a spoken word event or performance. Through this field trip, students can practice their active listening skills; and debriefing analysis, opinion, and interpretation afterwards, students can practice their critical interpretation skills. The Verses Festival of Words runs every year, mid-April, in Vancouver. There is a youth stream within this festival, called Hullaboo, that encourages youth to become involved in the listening and performing of slam poetry.

\section{Regarding the Thirdspace}

I will define the safe community of students, teachers, and staff as a collection of hyphenated identities. The space that is created here is defined as a thirdspace, as a composite of individual fractals and hyphens. Only until individual hyphenations feel safe and definable can an evolving and dynamic thirdspace exist. What might a thirdspace in a classroom setting look like?

In The Location of Culture, Homi Bhabha (1994) states: "It is the inbetween space that carries the burden of the meaning of culture, and by exploring this Third Space, we may elude the politics of polarity and emerge as the others of our selves" (p. 39). Through shifting the focus of pedagogy on the process of artmaking rather than the product of art-making, teachers can help students access the Third Space within a creative context.

A Coltrane jazz solo and a Pollock-ian splatter painting both are rich in artistic knowledge, but also propelled by the beauty of uncertainty and indeterminacy embedded in the process of making these works. To review, some creative and process-based forms that create meaning through the in-between space include klangfarbenmelodie, remix, jazz improvisation, musical variations, calligrammes, and pointillism.

When we begin to explore this liminal space, not only do we shift the minds of young thinkers into stronger musicians, artists, and writers, but we also allow for them to more safely explore their own identities as learners.

Author Anais Nin (as cited in Nin \& Stuhlmann, 1966) was famous for her journals, and reflective, introspective, and poetic writing style. She states:

We do not grow absolutely, chronologically. We grow sometimes in one dimension, and not in another; unevenly. We grow partially. We are relative. We are mature in one realm, childish in another. The past, present, and future mingle and pull us backward, forward, or fix us in the present. We are made up of layers, cells, constellations. (p. 127)

If we as teachers are responsible for guiding the growth of the complex constellations of our students' learner identities, then it is important that we understand and nurture one star at a time. It is important to remember that identities are not static; that sometimes, one aspect of a learner's identity will burn out in order to make space for new explorations and new learnings. It is also important to remember that shifts in learner identity are not always linear or predictable, nor should they expected to be this way. 


\section{Conclusion}

Bringing it back to the beginning of this paper_klangfarbenmelodie-it is interesting to note that a term that is now seen in every classical music dictionary, and taught in almost all Western musical theory classes, was once regarded as too radical and abrasive on the ears.

Kursell (2013) writes about Schoenberg's process of using klangfarbenmelodie in his compositions, stating, "Schoenberg embraced the effect of the missing beginnings and endings of sounds for his music. This compositional device enabled him to create colorings that were unheard in orchestral music" (p. 193).

As learners, teachers, and thinkers, it is essential to embrace the liminal, in-between spaces of artistic pedagogy. It is important to look past spaces of cultural and linguistic discomfort. It is essential to take risks in the creative process, because it is only through this modelling that our students will be encouraged to trust and thrive in their personal artistic expressions. Learning occurs in the gray space in between the black and white keys, in the brush strokes between English and Chinese, in the scratchy vinyl static of a remixed spoken word poem, of the meanderings of a new jazz variation, and in the nebulous territory between image and text of a calligramme. It goes without question that these spaces challenge us, but it is only through this that we can strengthen ourselves as thinkers, teachers, and students. Let us not be limited by the in-between space, but let us allow this hyphenated and complex space to be an avenue for exploration and enhancement of self. In the words of the jazz-inspired beat writer, Jack Kerouac (1957/1976), "There was nowhere to go but everywhere, so just keep on rolling under the stars" (p. 26).

\section{References}

Apollinaire, G., Greet, A. H., \& Lockerbie, S. I. (2004). Calligrammes: Poems of peace and war (1913-1916). Berkeley, CA: University of California Press.

Bhabha, H. (1994). The location of culture. London: Routledge.

Compton, W. (2003). The reinventing wheel: On blending the poetry of cultures through hip hop turntablism.

Retrieved from https://web.archive.org/web/20160314232309/http://www.horizonzero.ca/textsite/ remix.php?is $=8 \&$ file $=7 \&$ tlang $=0$

Compton, W., \& De Couto, J. (2010). "Turntable poetry, mixed-race, and schizophonophilia." doi:http://dx.doi.org/10.14288/1.0354387

De Mul, J. (2011). Horizons of hermeneutics: Intercultural hermeneutics in a globalizing world. Frontiers of Philosophy in China, 6(4), 628-655. Retrieved from http://www.jstor.org/stable/44259327

Harper, G. (2003). "Exterior form-interior substance: A conversation with Xu Bing." Sculpture 22, no. 1 (January-February 2003), 46-51.

Kerouac, J. (1957/1976). On the road. New York, NY: Penguin Books. 
Koyczan, S. (2017). Inconvenient skin [Recorded by S. Koyczan, featuring T. Tagaq and K. Gouchie]. On Inconvenient skin. Retrieved from https://shanekoyczan.com/track/1346257/inconvenient-skin

Kursell, J. (2013). Experiments on tone color in music and acoustics: Helmholtz, Schoenberg, and Klangfarbenmelodie. Osiris, 28(1), 191-211. doi:10.1086/671377

Nakagawa, A.M. (Director). (2005). Between: Living in the hyphen. National Film Board of Canada. Retrieved from www.nfb.ca/film/between_living_in_the_hyphen/.

Nin, A., \& Stuhlmann, G. (1966). The diary of Anais Nin. New York, NY: Swallow Press.

Sansom, M. (2001). Imaging music: Abstract expressionism and free improvisation. Leonardo Music Journal, 11, 29-34. Retrieved from http://www.jstor.org/stable/1513424

Wah, F. (1992). Alley alley home free. Red Deer, AB, Canada: Red Deer College Press.

Wah, F., \& Cabri, L. (2009). The false laws of narrative: The poetry of Fred Wah. Waterloo, ON: Wilfrid Laurier University Press.

Wexler, A. (2001). Bringing image and language together: A workshop at the Lehman College Art Gallery. Art Education, 54(4), 33-37. doi:10.2307/3193901

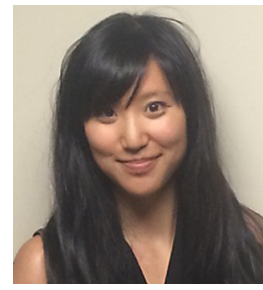

Sophia Xiang is a Grade 5/6 French Immersion teacher and school choir director in British Columbia. With her background in music and performance, she is passionate about using the fine arts to enhance and complement her students' learning experiences in the classroom and in the school community. Sophia is working towards her Master of Education at the University of British Columbia, with a focus on Language and Literacy Education. 